\title{
Nonalcoholic fatty liver disease in obese and nonobese pediatric patients
}

Eun Jeong Kim, MD, Hyun Jin Kim, MD

Department of Pediatrics, Inje University Busan Paik Hospital, Inje University College of Medicine, Busan, Korea

Purpose: Obesity is risk factor for nonalcoholic fatty liver disease (NAFLD). However, nonobese patients are also increasingly susceptible to NAFLD. The aim of this study was to compare the clinical characteristics of obese and nonobese pediatric patients with NAFLD.

Methods: We retrospectively studied 68 patients who were diagnosed with NAFLD between January 2010 and October 2016 at 10-18 years of age. Body mass index $\geq 95$ th percentile for age and sex was defined as obesity. Abdominal ultrasonography and laboratory, anthropometrics measurements were evaluated.

Results: Among the 68, 26 (38.2\%) were nonobese patients. The ratio of male to female was 5.8:1, and the median age at diagnosis was 13 years (range, 10-17 years). Significant higher triglyceride (223.0 $\mathrm{mg} / \mathrm{dL}$ vs. $145.9 \mathrm{mg} / \mathrm{dL}, P=0.047$ ) and total cholesterol levels ( $211.6 \mathrm{mg} / \mathrm{dL}$ vs. $173.2 \mathrm{mg} / \mathrm{dL}, P=0.011$ ) were shown in nonobese than obese patients. High-density lipoprotein cholesterol level $<40 \mathrm{mg} / \mathrm{dL}$ (hazard ratio [HR], 6.5; 95\% confidence interval [Cl], 2.13-7.10; $P=0.048$ ), total cholesterol level $>200$ $\mathrm{mg} / \mathrm{dL}$ (HR, 5.6; 95\% Cl, 1.23-15.31; $P=0.038$ ) and abdominal obesity (HR, 2.53; 95\% Cl, 1.22-4.68; $P=0.013$ ) were significant risk factors for NAFLD in nonobese patients.

Conclusion: Nonobese patients present a substantial proportion of pediatric NAFLD cases. Significant abnormal lipid concentrations were found in nonobese and abdominal obesity was important risk factor for nonobese NAFLD.

Key words: Body mass index, Nonalcoholic fatty liver disease, Cholesterol, Metabolic disease, Pediatric obesity

\section{Introduction}

Nonalcoholic fatty liver disease (NAFLD) is caused by excessive fat accumulation in the liver and can lead to progressive fibrosis and liver cirrhosis. Progression to irreversible, end-stage liver disease could result in liver transplantation. ${ }^{1,2)}$ So, early detection and effective treatment is important. The Korea National Health and Nutrition Examination Survey ${ }^{3)}$ reported 8.9\% of NAFLD prevalence in children.

Obesity is known as the leading risk factor for NAFLD and screening is recommended for obese children and for overweight children with additional risk factors such as dyslipidemia, insulin resistance, central obesity. $\left.{ }^{4}\right)$ However, some children with NAFLD are not obese.

Besides obesity, other clinical and laboratory factors may be contributed to NAFLD. Das et al. ${ }^{6}$ reported the importance of body fat percentage suggesting normal body mass index (BMI) could be an independent risk factor for NAFLD. Recent study ${ }^{7)}$ identifying factors associated alanine aminotransferase (ALT) elevation; truncal obesity and obesity were significant independent predictors. Significant role of low levels of serum 25-hydroxyvitamin D in NAFLD was also reported independent of metabolic syndrome. ${ }^{8,9)}$
Corresponding author: Hyun Jin Kim, MD Department of Pediatrics, Busan Paik Hospital, Inje University College of Medicine, 75 Bokji-ro, Busanjin-gu, Busan 47392, Korea

Tel: +82-51-850-6127

Fax:+82-51-890-5804

E-mail: 107778@paik.ac.kr https://orcid.org/0000-0003-0279-7925

Received: 17 July, 2018

Revised: 4 September, 2018

Accepted: 17 September, 2018
Copyright (c) 2018 by The Korean Pediatric Society

This is an open-access article distributed under the terms of the Creative Commons Attribution NonCommercial License (http://creativecommons.org/ licenses/by-nc/4.0/) which permits unrestricted noncommercial use, distribution, and reproduction in any medium, provided the original work is properly cited. 
Nonobese NAFLD ranges from $12 \%$ to $16 \%$ in Korean adults. ${ }^{10-12)}$ In the United States, NAFLD ranges from 38\% in obese to $9.6 \%$ in children with normal-weight. ${ }^{13)}$

Despite, nonobese individuals account for a substantial proportion of NAFLD, less is known about this population, especially in pediatric patients.

This study aimed to evaluate the prevalence of nonobese patients in pediatric NAFLD and compare clinical characteristics of obese with NAFLD.

\section{Materials and methods}

\section{Study population}

Patients diagnosed with NAFLD between January 2010 and October 2016 at 10-17 years of age were included in this study. We retrospectively analyzed the data using the electronic medical records of patients. NAFLD was diagnosed on the basis of the bright or hyperechoic lesions on liver imaging and ALT level $\geq 30 \mathrm{IU} / \mathrm{L}$ with the exclusion of other diseases; autoimmune hepatitis, viral hepatitis, Wilson disease, history of hepatotoxic drugs. ${ }^{4,13,14)}$ Institutional Review Board (IRB) of Inje University Busan Paik Hospital approval was obtained in this retrospective study (approval number: 170080). The requirement for informed consent was exempted by the IRB.

\section{Clinical and biochemical evaluation}

BMI was calculated by using height and body weight that was measured by a trained technician. Waist circumference was measured at the midpoint between the edge of the last rib and iliac crest by a flexible measuring tape (1-mm accuracy).

The laboratory evaluation was performed after patients had fasted overnight and included measurement of aspartate aminotransferase (AST), ALT, $\gamma$-glutamyl transferase ( $\gamma$-GTP), total cholesterol, triglyceride, low-density lipoprotein (LDL) cholesterol, high-density lipoprotein (HDL) cholesterol, fasting blood glucose, uric acid, and 25-hydroxyvitamin D.

Asian populations use the different BMI cutoff points and we defined obesity as a BMI $\geq 95$ th percentile for age and sex or BMI $\geq 25 \mathrm{~kg} / \mathrm{m}^{2}$. A BMI $\geq 85$ th but $<95$ th percentile or BMI $22.5-24.9 \mathrm{~kg} /$ $\mathrm{m}^{2}$ was defined as "overweight". ${ }^{15-17)}$ Waist circumference $\geq 90$ th percentile for age and sex was defined as abdominal obesity. ${ }^{18)}$

Among the different cutoff values for laboratory profiles to lipid and blood glucose, we used the reference values of International Diabetes Federation for fasting glucose, triglyceride, and HDL cholesterol. ${ }^{18)}$ For LDL cholesterol and total cholesterol, we used the reference values of The National Heart, Lung, and Blood Institute. ${ }^{19)}$

Abnormal laboratory concentrations were defined as follows; ${ }^{18,19)}$ Fasting glycemia $\geq 100 \mathrm{mg} / \mathrm{dL}$, triglycerides $\geq 150 \mathrm{mg} / \mathrm{dL}$, LDL cholesterol $>130 \mathrm{mg} /$ day, HDL cholesterol $<40 \mathrm{mg} / \mathrm{dL}(<50 \mathrm{mg} / \mathrm{dL}$ in female over 16 years), and total cholesterol $\geq 200 \mathrm{mg} / \mathrm{dL}$. Uric acid level of $\geq 6.5 \mathrm{mg} / \mathrm{dL}$ in female or $\geq 7 \mathrm{mg} / \mathrm{dL}$ in male was defined as hyperuricemia. $^{20)}$

1-25 dihydroxyvitamin $\mathrm{D}$ could be regulated by calcium, parathyroid hormone and we measured 25-hydroxyvitamin $\mathrm{D}$, which is considered as a best available indicator of vitamin D status. ${ }^{21)}$

Liver imaging were performed by a specialized one radiologist and grading of the fat infiltration was recorded as mild, moderate, and severe. ${ }^{22)}$

\section{Statistical analysis}

Continuous data were expressed as the median or mean \pm standard deviation and interquartile range. They were compared using the Mann-Whitney $U$ test or Student $t$ test. Discrete data were expressed as numbers and percentages and compared using Fisher exact or chi-square tests. To evaluate risk factors associated with the NAFLD, we used the hazard ratios (HRs) of the logistic regression models. A $P$ value of $<0.05$ was considered statistically significant. All prognostic variables with a $P$ value of $<0.1$ in univariate analysis were included in the multivariate analysis. Statistical analyses were performed using IBM SPSS ver. 18.0 (IBM Co., Armonk, NY, USA).

\section{Results}

\section{Baseline characteristics of NAFLD}

Of the 68 patients included in this study, 58 (85.3\%) were males, and $10(14.7 \%)$ were females. The median age at diagnosis was 13 years (range, 10-17 years) and the ratio of male-to female ratio was 5.8:1. Mean triglyceride level $(182.1 \mathrm{mg} / \mathrm{dL})$ was higher than the normal range; however, mean 25-hydroxyvitamin D level (25.6 ng/ $\mathrm{mL}$ ) was within the normal range. Mean uric acid level (6.8 mg/dL) was in the upper normal range. Approximately, 60\% and 30\% of patients had increased levels of triglyceride and uric acid, respectively. According to ultrasonographic findings, mild, moderate, and severe grade was shown in 22 (55.5\%), 27 (40\%), and 19 patients (4.5 $\%$, respectively. The baseline characteristics of the NAFLD patients are shown in Table 1.

\section{Differences between obese and nonobese patients}

Of the 68 patients, 42 (61.8\%) were obese, and 26 (38.2\%) were nonobese. Among the nonobese patients, 10 (38.5\%) were normalweight and 16 (61.5\%) were overweight patients. Males were predominant in both groups, and median age at diagnosis was similar between groups.

Significant higher triglyceride $(223.0 \mathrm{mg} / \mathrm{dL}$ vs. $145.9 \mathrm{mg} / \mathrm{dL}$, $P=0.047)$ and total cholesterol levels $(211.6 \mathrm{mg} / \mathrm{dL}$ vs. $173.2 \mathrm{mg} /$ $\mathrm{dL}, P=0.011$ ) were shown in nonobese than obese patients. Normalweight patients had significantly lower HDL cholesterol levels (35.4 mg/dL vs. $48.2 \mathrm{mg} / \mathrm{dL}, P=0.023$ ) than overweight patients. 
Table 1. Baseline characteristics of nonobese and obese patients with nonalcoholic fatty liver disease

\begin{tabular}{|c|c|c|c|c|}
\hline Variable & Total $(n=68)$ & Nonobese $(n=26)$ & Obese $(n=42)$ & $P$ value \\
\hline Age (yr) & $13(10-17)$ & $13(10-17)$ & $13(10-17)$ & 0.703 \\
\hline Male sex & $58(85.3)$ & $24(92.3)$ & $34(80.9)$ & 0.627 \\
\hline Abdominal obesity & 60 (88.2) & $18(69.2)$ & $42(100)$ & 0.053 \\
\hline Total cholesterol (mg/dL) & $188.3 \pm 40.6$ & $211.6 \pm 38.1$ & $173.2 \pm 35.5$ & 0.011 \\
\hline Triglyceride (mg/dL) & $182.1 \pm 89.5$ & $223.0 \pm 107.6$ & $145.9 \pm 63.9$ & 0.047 \\
\hline LDL cholesterol (mg/dL) & $121.9 \pm 33.8$ & $129.4 \pm 37.2$ & $115.4 \pm 30.3$ & 0.299 \\
\hline HDL cholesterol (mg/dL) & $45.0 \pm 8.6$ & $42.4 \pm 9.9$ & $46.8 \pm 7.3$ & 0.200 \\
\hline Fasting glucose (mg/dL) & $93.2 \pm 8.2$ & $85.3 \pm 7.5$ & $90.2 \pm 8.5$ & 0.153 \\
\hline AST (IU/L) & $82.7 \pm 72.9$ & $90.8 \pm 55.7$ & $77.5 \pm 83.3$ & 0.618 \\
\hline ALT (IU/L) & $168.8 \pm 152.7$ & $169.3 \pm 124.8$ & $168.5 \pm 171.5$ & 0.988 \\
\hline$\gamma-G T P(I U / L)$ & $50.5 \pm 31.5$ & $35.4 \pm 32.4$ & $42.3 \pm 30.5$ & 0.258 \\
\hline 25-Hydroxyvitamin D (ng/mL) & $25.6 \pm 14.0$ & $24.5 \pm 13.6$ & $26.7 \pm 15.6$ & 0.798 \\
\hline Uric acid (mg/dL) & $6.8 \pm 1.9$ & $6.7 \pm 1.8$ & $6.9 \pm 2.2$ & 0.305 \\
\hline Ultrasonographic grade & & & & 0.244 \\
\hline Mild & $22(32.4)$ & $12(46.1)$ & $10(23.8)$ & \\
\hline Moderate & 27 (39.7) & $6(23.1)$ & $21(50.0)$ & \\
\hline Severe & 19 (27.9) & $8(30.8)$ & 11 (26.2) & \\
\hline
\end{tabular}

Values are presented as a median (range), number (\%), and mean \pm standard deviation.

LDL, Iow-density lipoprotein; HDL, high-density lipoprotein; AST, aspartate aminotransferase; ALT, alanine aminotransferase; $\gamma$-GTP, $>$-glutamyl transferase.

Table 2. Baseline characteristics of normal-weight, overweight, and obese patients with nonalcoholic fatty liver disease

\begin{tabular}{|c|c|c|c|c|}
\hline Variable & Normal $(n=10)$ & Overweight ( $n=16)$ & Obese $(n=42)$ & $P$ value \\
\hline Age (yr) & $13(10-17)$ & $13(10-17)$ & $13(10-17)$ & 0.853 \\
\hline Male sex & $8(80)$ & $16(100)$ & $34(80.9)$ & 0.230 \\
\hline Abdominal obesity & $2(20)$ & $16(100)$ & $42(100)$ & 0.033 \\
\hline Total cholesterol (mg/dL) & $196.0 \pm 30.6$ & $220.6 \pm 41.4$ & $173.2 \pm 35.5$ & 0.025 \\
\hline Triglyceride (mg/dL) & $275.3 \pm 85.6$ & $193.1 \pm 13.1$ & $145.9 \pm 63.9$ & 0.042 \\
\hline LDL cholesterol (mg/dL) & $127.0 \pm 25.6$ & $131.1 \pm 45.7$ & $115.3 \pm 30.3$ & 0.577 \\
\hline HDL cholesterol (mg/dL) & $35.4 \pm 4.3$ & $48.2 \pm 9.6$ & $46.8 \pm 7.3$ & 0.014 \\
\hline Fasting glucose (mg/dL) & $83.2 \pm 8.2$ & $86.5 \pm 7.8$ & $90.2 \pm 8.5$ & 0.089 \\
\hline AST (IU/L) & $98.0 \pm 48.3$ & $86.3 \pm 62.6$ & $77.5 \pm 83.3$ & 0.852 \\
\hline ALT (IU/L) & $172.6 \pm 109.7$ & $167.3 \pm 140.7$ & $168.5 \pm 171.5$ & 0.998 \\
\hline$\gamma$-GTP (IU/L) & $40.2 \pm 38.2$ & $38.0 \pm 33.5$ & $42.3 \pm 30.5$ & 0.178 \\
\hline 25-hydroxyvitamin D (ng/mL) & $22.5 \pm 16.5$ & $28.5 \pm 8.4$ & $26.7 \pm 15.6$ & 0.876 \\
\hline Uric acid (mg/dL) & $6.9 \pm 1.4$ & $6.3 \pm 3.2$ & $6.9 \pm 2.2$ & 0.525 \\
\hline Ultrasonographic grade & & & & 0.185 \\
\hline Mild & $4(40.0)$ & $8(50.0)$ & $10(23.8)$ & \\
\hline Moderate & $3(30.0)$ & $3(18.8)$ & $21(50.0)$ & \\
\hline Severe & $3(30.0)$ & $5(31.2)$ & 11 (26.2) & \\
\hline
\end{tabular}

Values are presented as a median (range), number (\%), and mean \pm standard deviation.

LDL, low-density lipoprotein; HDL, high-density lipoprotein; AST, aspartate aminotransferase; ALT, alanine aminotransferase; $\gamma$-GTP, $\gamma$-glutamyl transferase.

When compared with obesity patients, normal-weight patients had significantly lower HDL cholesterol (35.4 mg/dL vs. $46.8 \mathrm{mg} /$ $\mathrm{dL}, P=0.004)$ and higher triglyceride levels ( $275.3 \mathrm{mg} / \mathrm{dL}$ vs. 145.9 $\mathrm{mg} / \mathrm{dL}, P=0.005)$. Uric acid and 25-hydroxyvitamin D levels did not differ between groups. Mild ultrasonographic grade (46.1\% vs. 23.8\%) was more common in nonobese and moderate ultrasonogra- phic grade (23.1\% vs. 50.0\%) was more common in obese patients. However, significant difference was not noted.

Abdominal obesity was shown in 42 (100\%) of obese and 18 (69.2\%) of nonobese patients. The clinical characteristics of NAFLD patients classified as obese and nonobese are shown in Table 1, and classified as obese, overweight, and normal-weight are shown in 
Table 3. Univariate and multivariate Cox analysis for risk factors of nonalcoholic fatty liver disease in nonobese patients

\begin{tabular}{|c|c|c|c|c|}
\hline Variable & Univariate analysis & $P$ value & Multivariate analysis & $P$ value \\
\hline Male sex & $2.82(0.280-28.518)$ & 0.215 & - & \\
\hline Abdominal obesity & 2.53 (1.224-4.688) & 0.013 & $2.14(0.867-5.688)$ & 0.025 \\
\hline Total cholesterol >200 mg/dL & $5.64(1.230-15.319)$ & 0.038 & $1.96(0.247-15.661)$ & 0.523 \\
\hline Triglyceride $>150 \mathrm{mg} / \mathrm{dL}$ & $2.32(0.465-10.883)$ & 0.313 & - & \\
\hline LDL cholesterol >130 mg/dL & $1.25(0.225-6.383)$ & 0.442 & - & \\
\hline HDL cholesterol $<40$ mg/dL & $6.56(2.136-7.106)$ & 0.048 & $5.46(0.689-43.288)$ & 0.108 \\
\hline Fasting glucose $>100 \mathrm{mg} / \mathrm{dL}$ & $1.02(1.005-1.056)$ & 0.546 & - & \\
\hline $25-0 \mathrm{H}$ vitamin $\mathrm{D}<20 \mathrm{ng} / \mathrm{mL}$ & $0.78(0.060-7.352)$ & 0.741 & - & \\
\hline Hyperuricemia & $0.63(0.068-4.672)$ & 0.594 & - & \\
\hline
\end{tabular}

Values are presented as hazard ratio (95\% confidence interval).

LDL, low-density lipoprotein; HDL, high-density lipoprotein; 25-OH vitamin D, 25-hydroxyvitamin D.

Table 2.

\section{Factors associated with NAFLD in nonobese patients}

In univariate analysis, total cholesterol level $>200 \mathrm{mg} / \mathrm{dL}$ (HR, 5.6; 95\% CI, 1.23-15.31; $P=0.038)$, HDL cholesterol level $<40 \mathrm{mg} /$ $\mathrm{dL}$ (HR, 6.5; 95\% CI, 2.13-7.10; $P=0.048$ ) and abdominal obesity (HR, 2.53; 95\% CI, 1.22-4.68; $P=0.013$ ) were significant risk factors for NAFLD in nonobese patients. However, in multivariate analysis, only abdominal obesity (HR, 2.14; 95\% CI, 0.86-5.68; $P=0.025)$ was associated significantly with NALFD in nonobese patients. Table 3 shows risk factors associated with the NAFLD in nonobese patients.

\section{Discussion}

The prevalence of NAFLD is increasing with parallel with obesity rates. Younossi et al. ${ }^{23)}$ reported the middle east as the highest prevalence area for NAFLD and 25.24\% of global NAFLD prevalence. However, NAFLD also has been reported in nonobese patients, with higher mortality and more severe histological necroinflammation than in the obese. ${ }^{24]}$

In our study, 26 NAFLD patients (38.2\%) were nonobese. Although our sample size is small, nonobese patients were more common than have been reported in previous studies ${ }^{12,20,25)}$ of adults. Higher total cholesterol and triglyceride levels were observed in nonobese patients than in obese, and HDL cholesterol level of $<40$ $\mathrm{mg} / \mathrm{dL}$ was risk factor for NAFLD in nonobese patients. Sex, age and biochemical parameters including 25-hydroxyvitamin D and uric acid did not different significantly between the 2 groups.

The male predominance in this study, with ratio of 5.8:1, similar to that reported in other studies. ${ }^{26,27)}$ This result may be a consequence of the efficacy of estrogen suppresses visceral fat accumulation. ${ }^{28)}$ The male-to-female ratio and median age of diagnosis did not differ between the 2 groups.

Recently, abnormal uric acid levels have been identified as risk factor of NAFLD. Wijarnpreecha et al. ${ }^{29)}$ detected a positive associa- tion between NAFLD and increased uric acid levels. Although the development of NAFLD is a complex and multifactorial process, insulin resistance is an important contributing factor. Insulin resistance leads to hyperinsulinemia, which reduces uric acid renal excretion and increases synthesis of uric acid. ${ }^{30,31)}$ So, the association between NAFLD and serum uric acid levels could be explained by hyperinsulinemia.

In this study, hyperuricemia was not detected in NAFLD. However, mean uric acid levels were in the upper-normal range for both groups. A previous study ${ }^{32)}$ also reported that upper-normal range uric acid level was independently associated with NAFLD.

Previous studies ${ }^{10,11)}$ those conducted in adult nonobese patients with NAFLD reported higher levels of triglyceride and lower levels of HDL cholesterol were associated significantly with nonobese patients. Similar to these studies, abnormal triglyceride and HDLcholesterol levels were significantly associated with nonobese in our study, especially in normal weight patients.

Meta-analysis by Pang et al. ${ }^{33)}$ reported the significant role of central obesity on NAFLD independent of Obesity. In our study, abdominal obesity is significant risk factor for nonobese NAFLD. Waist circumference should be measured for early detection of NAFLD who had normal BMI.

This study has some limitations. First, the patients were from a single center, which may not be generalizable to all populations. The retrospective design of the study also may have introduced bias. Second, we did not have data from liver biopsies and therefore could not assess pathological severity and histological finding. However, most parents refuse this invasive procedure, and ultrasonography is considered sufficient for the diagnosis of NAFLD. Third, we did not have data concerning insulin resistance, the influence of pubertal development has not been assessed, and lysosomal acid lipase activity abnormality that recently considered as a cause of liver steatosis was not excluded in nonobese patients. However, the present study is the first in an Asian pediatric population to assess the incidence of nonobese NAFLD and differences between obese and nonobese patients. Future well-designed prospective population- 
based studies could resolve potential bias in these results.

In conclusion, nonobese patients present a substantial proportion of pediatric NAFLD cases.

Significant abnormal lipid concentrations were found and abdominal obesity was important risk factor for nonobese NAFLD.

\section{Conflicts of interest}

No potential conflict of interest relevant to this article was reported.

\section{References}

1. Doycheva I, Watt KD, Rifai G, Abou Mrad R, Lopez R, Zein NN, et al. Increasing burden of chronic liver disease among adolescents and young adults in the USA: a silent epidemic. Dig Dis Sci 2017;62: 1373-80.

2. Wong RJ, Aguilar M, Cheung R, Perumpail RB, Harrison SA, Younossi ZM, et al. Nonalcoholic steatohepatitis is the second leading etiology of liver disease among adults awaiting liver transplantation in the United States. Gastroenterology 2015;148:547-55.

3. Kang Y, Park S, Kim S, Koh H. Normal serum alanine aminotransferase and non-alcoholic fatty liver disease among Korean adolescents: a cross-sectional study using data from KNHANES 2010-2015. BMC Pediatr 2018;18:215.

4. Vos MB, Abrams SH, Barlow SE, Caprio S, Daniels SR, Kohli R, et al. NASPGHAN clinical practice guideline for the diagnosis and treatment of nonalcoholic fatty liver disease in children: recommendations from the Expert Committee on NAFLD (ECON) and the North American Society of Pediatric Gastroenterology, Hepatology and Nutrition (NASPGHAN). J Pediatr Gastroenterol Nutr 2017;64:319-34.

5. Park JS, Seo JH, Youn HS. Gut microbiota and clinical disease: obesity and nonalcoholic Fatty liver disease. Pediatr Gastroenterol Hepatol Nutr 2013;16:22-7.

6. Das K, Das K, Mukherjee PS, Ghosh A, Ghosh S, Mridha AR, et al. Nonobese population in a developing country has a high prevalence of nonalcoholic fatty liver and significant liver disease. Hepatology 2010;51:1593-602.

7. Kim JW, Lee KJ, Yang HR, Chang JY, Moon JS, Khang YH, et al. Prevalence and risk factors of elevated alanine aminotransferase among Korean adolescents: 2001-2014. BMC Public Health 2018;18: 617.

8. Rhee EJ, Kim MK, Park SE, Park CY, Baek KH, Lee WY, et al. High serum vitamin D levels reduce the risk for nonalcoholic fatty liver disease in healthy men independent of metabolic syndrome. Endocr J 2013;60:743-52.

9. Targher G, Bertolini L, Scala L, Cigolini M, Zenari L, Falezza G, et al. Associations between serum 25-hydroxyvitamin D3 concentrations and liver histology in patients with non-alcoholic fatty liver disease. Nutr Metab Cardiovasc Dis 2007;17:517-24.

10. Kim HJ, Kim HJ, Lee KE, Kim DJ, Kim SK, Ahn CW, et al. Metabolic significance of nonalcoholic fatty liver disease in nonobese, nondiabetic adults. Arch Intern Med 2004;164:2169-75.

11. Kwon YM, Oh SW, Hwang SS, Lee C, Kwon H, Chung GE. Association of nonalcoholic fatty liver disease with components of metabolic syndrome according to body mass index in Korean adults. Am J Gastroenterol 2012;107:1852-8.
12. Cho HC. Prevalence and factors associated with nonalcoholic fatty liver disease in a nonobese Korean population. Gut Liver 2016;10: 117-25.

13. Vajro P, Lenta S, Socha P, Dhawan A, McKiernan P, Baumann U, et al. Diagnosis of nonalcoholic fatty liver disease in children and adolescents: position paper of the ESPGHAN Hepatology Committee. J Pediatr Gastroenterol Nutr 2012;54:700-13.

14. Schwimmer JB, Dunn W, Norman GJ, Pardee PE, Middleton MS, Kerkar N, et al. SAFETY study: alanine aminotransferase cutoff values are set too high for reliable detection of pediatric chronic liver disease. Gastroenterology 2010;138:1357-64, 1364.e1-2.

15. Chitturi S, Farrell GC, Hashimoto E, Saibara T, Lau GK, Sollano JD, et al. Non-alcoholic fatty liver disease in the Asia-Pacific region: definitions and overview of proposed guidelines. J Gastroenterol Hepatol 2007;22:778-87.

16. WHO Expert Consultation. Appropriate body-mass index for Asian populations and its implications for policy and intervention strategies. Lancet 2004;363:157-63.

17. Moon JS, Lee SY, Nam CM, Choi JM, Choe BK, Seo JW, et al. 2007 Korean National Growth Charts: review of developmental process and an outlook. Korean J Pediatr 2008;51:1-25.

18. Zimmet P, Alberti G, Kaufman F, Tajima N, Silink M, Arslanian S, et al. The metabolic syndrome in children and adolescents. Lancet 2007;369:2059-61.

19. Expert Panel on Integrated Guidelines for Cardiovascular Health and Risk Reduction in Children and Adolescents; National Heart, Lung, and Blood Institute. Expert panel on integrated guidelines for cardiovascular health and risk reduction in children and adolescents: summary report. Pediatrics 2011;128 Suppl 5:S213-56.

20. Chen CH, Huang MH, Yang JC, Nien CK, Yang CC, Yeh YH, et al. Prevalence and risk factors of nonalcoholic fatty liver disease in an adult population of taiwan: metabolic significance of nonalcoholic fatty liver disease in nonobese adults. J Clin Gastroenterol 2006;40: 745-52.

21. Holick MF. Vitamin D deficiency. N Engl J Med 2007;357:266-81.

22. Mofrad P, Contos MJ, Haque M, Sargeant C, Fisher RA, Luketic VA, et al. Clinical and histologic spectrum of nonalcoholic fatty liver disease associated with normal ALT values. Hepatology 2003;37:1286-92.

23. Younossi ZM, Koenig AB, Abdelatif D, Fazel Y, Henry L, Wymer M. Global epidemiology of nonalcoholic fatty liver disease-Metaanalytic assessment of prevalence, incidence, and outcomes. Hepatology 2016;64:73-84.

24. Cruz AC, Bugianesi E, Cruz AC, George J, Day CP, Liaquat H, et al. Characteristics and long-term prognosis of lean patients with nonalcoholic fatty liver disease. Gastroenterology 2014;146(5 Suppl 1):S909.

25. Nishioji K, Sumida Y, Kamaguchi M, Mochizuki N, Kobayashi M, Nishimura T, et al. Prevalence of and risk factors for non-alcoholic fatty liver disease in a non-obese Japanese population, 2011-2012. J Gastroenterol 2015;50:95-108.

26. Mager DR, Ling S, Roberts EA. Anthropometric and metabolic characteristics in children with clinically diagnosed nonalcoholic fatty liver disease. Paediatr Child Health 2008;13:111-7.

27. Lazo M, Hernaez R, Eberhardt MS, Bonekamp S, Kamel I, Guallar E, et al. Prevalence of nonalcoholic fatty liver disease in the United States: the Third National Health and Nutrition Examination Survey, 19881994. Am J Epidemiol 2013;178:38-45.

28. Omagari K, Kadokawa Y, Masuda J, Egawa I, Sawa T, Hazama H, et al. Fatty liver in non-alcoholic non-overweight Japanese adults: incidence and clinical characteristics. J Gastroenterol Hepatol 2002;17: 1098-105.

29. Wijarnpreecha K, Panjawatanan P, Lekuthai N, Thongprayoon C, 
Cheungpasitporn W, Ungprasert P. Hyperuricaemia and risk of nonalcoholic fatty liver disease: a meta-analysis. Liver Int 2017;37: 906-18.

30. Quiñones Galvan A, Natali A, Baldi S, Frascerra S, Sanna G, Ciociaro $D$, et al. Effect of insulin on uric acid excretion in humans. Am J Physiol 1995;268(1 Pt 1):E1-5.

31. Buzzetti E, Pinzani M, Tsochatzis EA. The multiple-hit pathogenesis of non-alcoholic fatty liver disease (NAFLD). Metabolism 2016;65:103848.

32. Hwang IC, Suh SY, Suh AR, Ahn HY. The relationship between normal serum uric acid and nonalcoholic fatty liver disease. J Korean Med Sci 2011;26:386-91.

33. Pang Q, Zhang JY, Song SD, Qu K, Xu XS, Liu SS, et al. Central obesity and nonalcoholic fatty liver disease risk after adjusting for body mass index. World J Gastroenterol 2015;21:1650-62. 